\title{
Sharing of nitrogen between connected ramets of Alternanthera philoxeroides in homogeneous environments
}

\section{Bi-Cheng Dong}

Beijing Forestry University

\section{Pu Wang}

the Chinese Academy of Sciences

Fang-Li Luo ( $\square$ ecoluofangli@163.com )

Beijing Forestry University

\section{Research Article}

Keywords: Alternanthera philoxeroides, clonal plants, directional transport, $15 \mathrm{~N}$ isotope trace, partitioning of $\mathrm{N}$, physiological integration

Posted Date: February 21 st, 2022

DOI: https://doi.org/10.21203/rs.3.rs-1353280/v1

License: (c) (i) This work is licensed under a Creative Commons Attribution 4.0 International License. Read Full License 


\section{Abstract}

\section{Purpose}

The benefits of clonal integration have been widely documented in clonal species, but quantitative tests of the movement of resources between connected ramets (e.g., transport rate and partitioning pattern of nitrogen) are still scarce.

\section{Methods}

We conducted a control experiment with the clonal species Alternanthera philoxeroides, and used ${ }^{15} \mathrm{~N}$ isotope to quantify the transport rate of nitrogen $(\mathrm{N})$ in two opposite directions (i.e., either from younger to older ramets or from older to younger ramets) within one clone, and the partitioning proportion of $\mathrm{N}$ in recipient ramets.

\section{Results}

The amount of ${ }^{15} \mathrm{~N}$ transported toward the apical part was markedly reduced at the higher external $\mathrm{N}$ level, whereas the amount of ${ }^{15} \mathrm{~N}$ transported toward the basal part was unrelated to the external $\mathrm{N}$ levels. The rate of ${ }^{15} \mathrm{~N}$ acropetal transport basically averaged $20.9 \%$, and the rate of ${ }^{15} \mathrm{~N}$ basipetal transport generally ranged between $0.2 \%$ and $6.3 \%$, both being negatively dependent of DPNC (i.e., the difference in plant $\mathrm{N}$ concentration [PNC] between apical and basal parts). The proportion of ${ }^{15} \mathrm{~N}$ in stems and in leaves averaged $74.7 \%$ and $18.1 \%$, respectively; the proportion of root ${ }^{15} \mathrm{~N}$ in the apical part significantly decreased from $7.6 \%$ to $0.4 \%$ when acropetal transport occurred.

\section{Conclusion}

These results suggest that $\mathrm{N}$ sharing between connected ramets tended to be acropetal in $A$. philoxeroides and the partitioning pattern of $\mathrm{N}$ is organ-specific, which potentially contributes to the early development of young ramets, and also to the spread and abundance of $A$. philoxeroides in limited $\mathrm{N}$ conditions.

\section{Introduction}

Clonal integration is a distinguishing life-history trait of clonal species that allows for the transport and sharing of internal resources (e.g., carbohydrates, water, and mineral nutrients) among connected ramets within the same clone (Alpert and Mooney 1986; de Kroon and van Groenendael 1997; Song et al. 2013; Wang et al. 2021). Numerous studies have demonstrated that such physiological integration can improve the performance of clones in heterogeneous environments, where connected ramets experience different levels of external resources such as light, water, or nitrogen (Alpert 1996; de Kroon and Fransen 1996; Hutchings and Wijesinghe 1997; Xu et al. 2010; Song et al. 2013; Roiloa et al. 2014; Huang et al. 2018; Wang et al. 2021). However, relative a few studies have directly explored the mode (e.g., direction and 
strength) of clonal integration in homogeneous environments (Dong et al. 2015; Zhang et al. 2016; Wang et al. 2017; Xi et al. 2019). This is partly because the performance of clonal fragments in homogeneous environments has often been treated as an experimental control for effects of integration, with the assumption that clonal integration tends to impose no effect when resource availability is spatially uniform (Song et al. 2013; Wang et al. 2021). However, an increasing body of studies have suggested that, even in homogeneous environments, variation in the developmental age of individual ramets could cause differences in the ability of ramets to obtain external resources, in addition to any internal gradient in resource availability (Alpert 1996; Roiloa et al. 2013; Dong et al. 2015; Xi et al. 2019). Such physiological differences may thus trigger the movement of internal resources among ramets and influence the fitness of clones in homogeneous environments. The ecological significance of clonal integration in homogeneous environments should thus be taken into consideration.

One concern regarding clonal integration in homogeneous environments is the sharing of nitrogen $(\mathrm{N})$ among ramets of clonal species (Alpert 1996, 2002; Xu et al. 2010; Roiloa et al. 2014). Typically, clones tend to show a directional transfer of N, e.g., from older to younger ramets (Marshall and Anderson-Taylor 1992; Alpert 1996). For example, in the stoloniferous species Fragaria chiloensis, which can produce individual ramets at different developmental ages within one growth season, older ramets that have established roots can actively supply internal resources to younger ramets with developing roots that have a limited uptake ability; thereby, by sharing resources, they can increase the fitness of the whole clone (Marshall and Anderson-Taylor 1992; Alpert 1996, 2002). Indeed, the occurrence of directional transport of $\mathrm{N}$ may be based on the condition that $\mathrm{N}$ sharing is driven by the source-sink relationship of internal resource supply (Alpert 1999). Furthermore, $\mathrm{N}$ sharing may be constrained by plant organ structures such as sectorilaity and physiological constraints, e.g., the formation of discrete integrated physiological units (IPUs) might strengthen, to some degree, the directional transport of resources through connections (Marshall and Price 1997). However, to our knowledge, quantitative tests of the rate of directional transport of $\mathrm{N}$ via connections in clonal species is lacking (Marshall and Anderson-Taylor 1992; Alpert 1996; Xu et al. 2010).

In addition, the rate of $\mathrm{N}$ transport via connections may also depend on external resource availability (Dong et al. 2015). One common scenario is that the performance of younger ramets within one clone may be limited by their inherent uptake capacity during the early developmental age; thus, younger ramets may strongly depend on the supply of $\mathrm{N}$ from older ramets (Stuefer 1998; Roiloa et al. 2013; Dong et al. 2015). Therefore, a plausible prediction is that an increase in external resource availability may strengthen the donor role of older ramets in sharing resources between ramets; this may thereby increase the transfer rate of $\mathrm{N}$, particularly when the direction of $\mathrm{N}$ transport was already toward younger ramets. Correspondingly, the net effect of integration on clonal performance should be more positive at higher levels of external resource supply (Dong et al. 2015; Xi et al. 2019).

Another concern in this paper is about the partitioning pattern of $\mathrm{N}$ among plant organs in recipient ramets of clonal fragments. Provided that recipient ramets obtain $\mathrm{N}$ via clonal integration, rather than from an external supply, the additional $\mathrm{N}$ imported from donor ramets also needs to be redistributed 
among different organs of recipient ramets. The partitioning pattern of $\mathrm{N}$ among organs thus becomes a key process in determining the individual growth and development of recipient ramets. Although the exact partitioning pattern of internal resources in recipient ramets of clonal species is still not fully known, previous studies on the relationship between $\mathrm{N}$ uptake and vegetative growth of individual plants have provided two important clues (Hirose 1986, 1987). First, the partitioning of resources among organs may be proportional to (e.g., linearly related to) the $\mathrm{N}$ concentration of the whole plant, e.g., in Agrostis vinealis and Corynephorus canescens (Boot et al. 1992), Polygonum cuspidatum (Hirose 1987), and Quercus serrata (Hikosaka et al. 2005). Second, each different plant organ possesses its own priority for $\mathrm{N}$ utilization, and the priorities determine the developmental trajectory of the plants. For example, leaves of P. cuspidatum could utilize $60 \%$ of $\mathrm{N}$ taken up by the roots to construct photosynthetic tissues, whereas the relative investment of $\mathrm{N}$ in leaves of $A$. vinealis and $C$. canescens can decline to improve the development of stems and roots (Hirose 1987; Boot et al. 1992). Exploring the distribution pattern of $N$ among organs in recipient ramets may, therefore, help to clarify whether an additional supply of $\mathrm{N}$ results in similar rules of $\mathrm{N}$ partitioning (as discussed above) via clonal integration for clonal species.

We conducted a control experiment with a typical wetland clonal species, Alternanthera philoxeroides, using ${ }^{15} \mathrm{~N}$ isotope to trace the movement of $\mathrm{N}$ either toward young ramets or toward older ramets within clonal fragments (i.e., acropetal and basipetal transport of $\mathrm{N}$ via connections). This allowed us to quantify the transport rate of $\mathrm{N}$ in two opposite directions and the partitioning of $\mathrm{N}$ in recipient ramets at two contrasting $\mathrm{N}$ levels (i.e., high and low $\mathrm{N}$ availability). In particular, we addressed the following questions: (1) Is the sharing of $N$ between connected ramets bi-directional? (2) Does the transport rate of $\mathrm{N}$ depend on external resource availability? (3) Does the plant $\mathrm{N}$ concentration determine the partitioning pattern of $\mathrm{N}$ among different plant organs?

\section{Material And Methods}

Plant species

Alternanthera philoxeroides (Mart.) Griseb. (commonly called alligator weed) is an amphibious, perennial herb of the Amaranthaceae family, native to South America (Holm et al. 1997; Julien et al. 2012). The species is listed as one of the most invasive species in China (Li and Xie, 2002). Populations of $A$. philoxeroides in China have extremely low genetic diversity and rarely produce fertile seeds within an entire life cycle (Xu et al. 2003; Ye et al. 2003). Thus, the species mainly achieve offspring recruitment via vegetative means such as stolon and root fragments (Jia et al. 2009; Dong et al. 2010, 2012). Clones of A. philoxeroides can establish extensive networks of connected ramets, and clonal integration can remarkably promote the individual performance and the population expansion of $A$. philoxeroides (Wang et al. 2008; Yu et al. 2009; Xu et al. 2010; Dong et al. 2015; Xi et al. 2019). A. philoxeroides has spread widely in both aquatic and terrestrial habitats, such as irrigation ditches and riparian crop fields, causing severe ecological and environmental problems (Pan et al. 2006; Wu et al. 2016). 
On December 9, 2016, 150 stolon fragments of $A$. philoxeroides were collected from three separate populations (approx. $>500 \mathrm{~m}$ apart) in a riparian agricultural area $\left(28.87^{\circ} \mathrm{N}, 121.01^{\circ} \mathrm{E}\right)$ in Taizhou City in Zhejiang Province, China. These stolon fragments were then transported to Beijing Forestry University in Beijing on December 10, 2016. On December 11, 2016, 30 similar-sized clonal fragments were randomly selected for the experiment and classified into two parts. One was defined as the "apical part" consisting of one main stem and one lateral branch, and the other as the "basal part" consisting of two relatively older lateral branches. The main stem and three branches each had three nodes (Fig. 1).

\section{Experimental design}

The experiment employed a two-way factorial design, with $\mathrm{N}$ level treatments (i.e., 40 or $120 \mathrm{mg} \mathrm{N} \mathrm{L}^{-1}$; Fig. 1) crossed with the position of ${ }^{15} \mathrm{~N}$ supply treatments (i.e., ${ }^{15} \mathrm{NO}_{3}{ }^{+}$supplied in the apical part or the basal part; Fig. 1a, b, d, and e). There were five replicates for each of four combined treatments. To explicitly measure the concentration of ${ }^{15} \mathrm{~N}$ derived from ${ }^{15} \mathrm{~N}$-labelled nitrate, five additional replicates of clonal fragments were used as a control treatment for each of the $\mathrm{N}$ levels (i.e., external ${ }^{15} \mathrm{NO}_{3}{ }^{+}$supplied in neither the apical part nor the basal part; Fig. 1c and f). Each of the clonal fragments was placed into a pair of adjacent plastic cups (with a $1000 \mathrm{~mL}$ capacity) with the apical part of the fragment in one cup, the basal part in the other, and the internode that connected the two parts running through matching notches in the rims of the cups. In the $\mathrm{N}$ level treatments, clonal fragments were grown in modified Hoagland solutions containing either 40 or $120 \mathrm{mg} \mathrm{N} \mathrm{L}^{-1}$, supplied as $\mathrm{Ca}\left(\mathrm{NO}_{3}\right)_{2}$, with 15 clonal fragments grown in each solution. We varied the concentration of $\mathrm{CaSO}_{4}$ between solutions to maintain the same total solute concentration and the same concentration of each nutrient except $\mathrm{SO}_{4}{ }^{-2}$ in each solution (Alpert et al. 2002; Wang et al. 2017). The modified Hoagland solution was refreshed every five days.

To test the acropetal transport of $\mathrm{N}$ between connected ramets, the basal parts of five clonal fragments in each of the $\mathrm{N}$ level treatments were labelled by $\mathrm{Ca}\left({ }^{15} \mathrm{NO}_{3}\right)_{2}$ (99.24 atom\%; Shanghai Research Institute of Chemical Industry, Shanghai, China), one day before the harvest. To test the basipetal transport of $\mathrm{N}$, the apical parts of another five clonal fragments in each of the $\mathrm{N}$ level treatments were similarly labelled with $\mathrm{Ca}\left({ }^{15} \mathrm{NO}_{3}\right)_{2}$. We used Hoagland solutions containing ${ }^{15} \mathrm{~N}$, where the amount of ${ }^{15} \mathrm{~N}$ from $\mathrm{Ca}\left({ }^{15} \mathrm{NO}_{3}\right)_{2}$ occupied $10 \%$ of the total amount of $\mathrm{N}$ in the solution. The plants receiving ${ }^{15} \mathrm{~N}$ supply treatments were allowed to take up ${ }^{15} \mathrm{~N}$ for $25 \mathrm{~h}$ and then were harvested. The plants in the control treatment (i.e., the remaining five clonal fragments in each $\mathrm{N}$ treatment) were not labelled by $\mathrm{Ca}\left({ }^{15} \mathrm{NO}_{3}\right)_{2}$ but were harvested at the same time.

The experiment was conducted at the Wetland Process Lab in the School of Nature Conservation, Beijing Forestry University, and it lasted for five weeks from December 12, 2016, to January 15, 2017. The mean room temperature during the experiment was $23.34 \pm 0.25^{\circ} \mathrm{C}$. The light source was supplied by fullspectrum LED lamps (Guangdong Shunde POVI Biological Technology Co., Ltd., Foshan, Guangdong) for $12 \mathrm{~h}$ of light per day. The irradiation level of lamps was kept at an average of $95 \mu \mathrm{mol} \mathrm{m}^{-1} \mathrm{~s}^{-1}$. 
Measurement and isotope analysis

At harvest, leaves, stems, and roots of the apical part and the basal part of clonal fragments were dried at $70^{\circ} \mathrm{C}$ for $48 \mathrm{~h}$, weighed to measure biomass, and ground using a Retsch MM400 Mixer Mill at a frequency of $28 \mathrm{~Hz}$ for 6 min (Retsch $\mathrm{GmbH}$, Haan, Germany). A subsample of $2 \mathrm{mg}$ powder was used to measure the $\mathrm{N}$ concentration and the atom $\%{ }^{15} \mathrm{~N}$ of leaves, stems, and roots, using a Flash 2000 Elemental Analyzer that was interfaced with a Delta V Isotope Ratio Mass Spectrometer (Thermo Fisher Scientific, Inc., USA).

\section{Data analysis}

In each of the $\mathrm{N}$ level treatments, atom $\%$ excess ${ }^{15} \mathrm{~N}$ (APE) was calculated by the atom\% ${ }^{15} \mathrm{~N}$ difference between plants in each of the $\mathrm{N}$ supply treatments (atom\% ${ }^{15} \mathrm{~N}_{\text {treatment }}$ ) and the ones in the control treatment (atom\% ${ }^{15} \mathrm{~N}_{\text {control }}$ ), i.e., APE = atom\% ${ }^{15} \mathrm{~N}_{\text {treatment }}$ - atom\% ${ }^{15} \mathrm{~N}_{\text {control }}$ (Gao et al. 2014; He et al. 2009). The ${ }^{15} \mathrm{~N}$ concentration of each plant organ ( $\mathrm{mg}^{15} \mathrm{~N} \mathrm{~g}^{-1} \mathrm{~d}$.w. plant organ) was calculated by multiplying the $\mathrm{N}$ content ( $\mathrm{mg} \mathrm{N} \mathrm{g}^{-1}$ d.w. plant organ) and APE. The amount of ${ }^{15} \mathrm{~N}$ in each plant organ (mg) was then calculated by multiplying the ${ }^{15} \mathrm{~N}$ concentration of the plant organ and the mass of the corresponding plant organ. The amount of ${ }^{15} \mathrm{~N}$ in the apical or basal part $(\mathrm{mg})$ was calculated according to the sum of the amount of ${ }^{15} \mathrm{~N}$ in the leaves, stems, and roots of the apical or basal part; thus, the ${ }^{15} \mathrm{~N}$ concentration of the apical or basal part (\%) was calculated by dividing the total ${ }^{15} \mathrm{~N}$ amount of the apical or the basal part by the mass of the corresponding part.

The partitioning proportion of ${ }^{15} \mathrm{~N}$ among organs (in either the apical part or basal part of clonal fragments) was calculated by dividing the amount of ${ }^{15} \mathrm{~N}$ in the plant organ by the total amount of ${ }^{15} \mathrm{~N}$ in the corresponding part (e.g., the apical or basal part). The rate of ${ }^{15} \mathrm{~N}$ transport toward recipient ramets was calculated by dividing the amount of ${ }^{15} \mathrm{~N}$ in recipient ramets by the total amount of ${ }^{15} \mathrm{~N}$ in the whole clonal fragment.

Two-way ANOVAs were used to test effects of the position of ${ }^{15} \mathrm{~N}$ supply (apical part $v s$. basal part) and $\mathrm{N}$ levels (40 vs. $120 \mathrm{mg} \mathrm{N} \mathrm{L}^{-1}$ ) on the amount of leaf ${ }^{15} \mathrm{~N}$, stem ${ }^{15} \mathrm{~N}$, root ${ }^{15} \mathrm{~N}$, and the total amount of ${ }^{15} \mathrm{~N}$ in the apical and basal parts of the clonal fragments of $A$. philoxeroides. Two-way ANOVAs were also used to test effects of the position of ${ }^{15} \mathrm{~N}$ supply (apical part vs. basal part) and $\mathrm{N}$ levels (40 vs. $120 \mathrm{mg}$ $\mathrm{NL}^{-1}$ ) on the partitioning proportion of leaf ${ }^{15} \mathrm{~N}$, stem ${ }^{15} \mathrm{~N}$, and root ${ }^{15} \mathrm{~N}$ of the apical or basal parts of clonal fragments. In addition, linear regressions were employed to examine the correlation between the transport rate of ${ }^{15} \mathrm{~N}$ toward recipient parts (transport rate of ${ }^{15} \mathrm{~N}=$ the amount of ${ }^{15} \mathrm{~N}$ in the recipient part/the total amount of ${ }^{15} \mathrm{~N}$ in the clonal fragment) and $\triangle \mathrm{PNC}(\triangle \mathrm{PNC}=$ the $\mathrm{N}$ concentration of the apical part - the $\mathrm{N}$ concentration of the basal part). Linear regressions were also employed to examine the correlation between the partitioning proportion of ${ }^{15} \mathrm{~N}$ of each plant organ (the amount of ${ }^{15} \mathrm{~N}$ in the plant organ/the total ${ }^{15} \mathrm{~N}$ in the apical or basal part) and PNC (the $\mathrm{N}$ concentration of the apical or basal part) 
of the apical part or the basal part of clonal fragments. Data that violated the assumptions of homogeneity of variance and normality were natural-log transformed. Data analyses were conducted using R v.4.1.1 (R Core Team 2021).

\section{Results}

Amount of ${ }^{15} \mathrm{~N}$ in plant organs

The amount of leaf ${ }^{15} \mathrm{~N}$, stem ${ }^{15} \mathrm{~N}$, root ${ }^{15} \mathrm{~N}$, and total amount of ${ }^{15} \mathrm{~N}$ in the apical part were significantly affected by position of ${ }^{15} \mathrm{~N}$ supply, but not by $\mathrm{N}$ levels (Table 1 ). The amount of leaf ${ }^{15} \mathrm{~N}$, stem ${ }^{15} \mathrm{~N}$, root ${ }^{15} \mathrm{~N}$, and total amount of ${ }^{15} \mathrm{~N}$ in the apical part was markedly greater when the apical part of the clonal fragment was injected by external ${ }^{15} \mathrm{~N}$ than when the basal part was injected (Fig. 2). Furthermore, the effect of position of ${ }^{15} \mathrm{~N}$ supply on the amount of leaf ${ }^{15} \mathrm{~N}$, stem ${ }^{15} \mathrm{~N}$, root ${ }^{15} \mathrm{~N}$, and total ${ }^{15} \mathrm{~N}$ in the apical part was or tended to be markedly stronger when plants were grown at the $\mathrm{N}$ level of $120 \mathrm{mg} \mathrm{L}^{-1}$ than at $40 \mathrm{mg} \mathrm{L}^{-1}$ (Fig. 2). 
Table 1

ANOVA results showing the effects of the position $(P)$ of ${ }^{15} \mathrm{~N}$ supply $\left({ }^{15} \mathrm{~N}\right.$ was supplied in either the apical or basal parts) and nitrogen $(\mathrm{N})$ levels (40 and 120 $\mathrm{mg} \mathrm{N} \mathrm{L}{ }^{-1}$ ) on the amounts of ${ }^{15} \mathrm{~N}$ in each plant organ in the apical and basal parts of clonal fragments of Alternanthera philoxeroides. $P$ values less than 0.05 are bold.

\begin{tabular}{|c|c|c|c|c|c|c|}
\hline & \multicolumn{2}{|c|}{ Position (P) } & \multicolumn{2}{|c|}{ Nitrogen $(\mathrm{N})$} & \multicolumn{2}{|l|}{$P \times N$} \\
\hline & $F_{1,16}$ & $P$ & $F_{1,16}$ & $P$ & $F_{1,16}$ & $P$ \\
\hline \multicolumn{7}{|l|}{ Apical } \\
\hline Total ${ }^{15} \mathrm{~N}$ & 20.41 & $<0.001$ & 0.49 & 0.494 & 4.02 & 0.062 \\
\hline Leaf ${ }^{15} \mathrm{~N}$ & 7.57 & 0.014 & 0.60 & 0.449 & 3.01 & 0.102 \\
\hline Stem ${ }^{15} \mathrm{~N}$ & 22.24 & $<0.001$ & 0.53 & 0.478 & 4.96 & 0.041 \\
\hline Root ${ }^{15} N^{\$}$ & 170.88 & $<0.001$ & 2.05 & 0.172 & 3.25 & 0.090 \\
\hline \multicolumn{7}{|l|}{ Basal } \\
\hline Total ${ }^{15} \mathrm{~N}^{\$}$ & 128.60 & $<0.001$ & 0.20 & 0.661 & 0.03 & 0.866 \\
\hline Leaf ${ }^{15} N^{\$}$ & 132.45 & $<0.001$ & 0.30 & 0.593 & $<0.01$ & 0.967 \\
\hline Stem ${ }^{15} N^{\$}$ & 108.26 & $<0.001$ & 0.10 & 0.753 & 0.06 & 0.811 \\
\hline Root ${ }^{15} \mathrm{~N}^{\$}$ & 100.91 & $<0.001$ & 0.37 & 0.551 & 0.24 & 0.633 \\
\hline
\end{tabular}

The amount of leaf ${ }^{15} \mathrm{~N}$, stem ${ }^{15} \mathrm{~N}$, root ${ }^{15} \mathrm{~N}$, and total ${ }^{15} \mathrm{~N}$ in the basal part was independently affected by the position of ${ }^{15} \mathrm{~N}$ supply but not by $\mathrm{N}$ levels or their interaction (Table 1). In contrast to the apical part, the amount of leaf ${ }^{15} \mathrm{~N}$, stem ${ }^{15} \mathrm{~N}$, root ${ }^{15} \mathrm{~N}$, and total ${ }^{15} \mathrm{~N}$ in the basal part was markedly greater when the basal part was injected by external ${ }^{15} \mathrm{~N}$ (Fig. 2).

Partitioning proportion of ${ }^{15} \mathrm{~N}$ in plant organs

Except for the proportion of ${ }^{15} \mathrm{~N}$ in the roots of the apical part, the proportion of ${ }^{15} \mathrm{~N}$ in other plant organs in either the apical or basal parts was not affected by the position of ${ }^{15} \mathrm{~N}$ supply or by $\mathrm{N}$ levels; thus, these levels were relatively fixed (Table 2). The proportions of leaf ${ }^{15} \mathrm{~N}$ and stem ${ }^{15} \mathrm{~N}$ in the apical part averaged $19.4 \%$ and $76.6 \%$, respectively, whereas the proportion of leaf ${ }^{15} \mathrm{~N}$, stem ${ }^{15} \mathrm{~N}$, and root ${ }^{15} \mathrm{~N}$ in the basal part averaged $16.9 \%, 72.8 \%$ and $10.3 \%$, respectively (Fig. 3a, b, d, e, and f). The proportion of root ${ }^{15} \mathrm{~N}$ in the apical part was significantly greater when the apical part was injected with external ${ }^{15} \mathrm{~N}$ than when the basal part was injected (7.6\% vs. $0.4 \%$, Fig. 3c). 
Table 2

ANOVA results showing the effects of position $(\mathrm{P})$ of ${ }^{15} \mathrm{~N}$ supply $\left({ }^{15} \mathrm{~N}\right.$ was supplied in either the apical or basal part) and nitrogen $(\mathrm{N})$ levels $\left(40\right.$ and $120 \mathrm{mg} \mathrm{N} \mathrm{L}^{-1}$ ) on proportion of ${ }^{15} \mathrm{~N}$ (plant-organ ${ }^{15} \mathrm{~N}$ amount/whole-part ${ }^{15} \mathrm{~N}$ amount) in each plant organ in the apical and basal parts of clonal fragments of Alternanthera philoxeroides. Pvalues less than 0.05 are bold.

\begin{tabular}{|c|c|c|c|c|c|c|}
\hline & \multicolumn{2}{|c|}{ Position (P) } & \multicolumn{2}{|c|}{ Nitrogen $(\mathrm{N})$} & \multicolumn{2}{|l|}{$P \times N$} \\
\hline & $F_{1,16}$ & $P$ & $F_{1,16}$ & $P$ & $F_{1,16}$ & $P$ \\
\hline \multicolumn{7}{|l|}{ Apical } \\
\hline Proportion of leaf ${ }^{15} \mathrm{~N}$ & 4.13 & 0.059 & 0.13 & 0.720 & 0.05 & 0.818 \\
\hline Proportion of stem ${ }^{15} \mathrm{~N}$ & 2.75 & 0.117 & 0.02 & 0.891 & 0.31 & 0.586 \\
\hline Proportion of root ${ }^{15} \mathrm{~N}$ & 38.81 & $<0.001$ & 0.10 & 0.755 & 0.43 & 0.522 \\
\hline \multicolumn{7}{|l|}{ Basal } \\
\hline Proportion of leaf ${ }^{15} \mathrm{~N}$ & 0.29 & 0.595 & 0.22 & 0.649 & 0.19 & 0.670 \\
\hline Proportion of stem ${ }^{15} \mathrm{~N}$ & 0.17 & 0.684 & 0.24 & 0.629 & 0.20 & 0.657 \\
\hline Proportion of root ${ }^{15} \mathrm{~N}$ & 0.01 & 0.943 & 0.06 & 0.813 & 0.05 & 0.832 \\
\hline \multicolumn{7}{|c|}{$\begin{array}{l}\text { Appendix Table } 1 \text { ANOVA results showing the effects of position }(\mathrm{P}) \text { of }{ }^{15} \mathrm{~N} \text { supply }\left({ }^{15} \mathrm{~N} \text { was supplied }\right. \\
\text { in either the apical or basal parts) and nitrogen }(\mathrm{N}) \text { levels }(40 \text { or } 120 \mathrm{mg} \mathrm{N} \mathrm{L}-1) \text { on the biomass of } \\
\text { each plant organ in the apical and basal parts of clonal fragments of Alternanthera philoxeroides. } P \\
\text { values less than } 0.05 \text { are bold. }\end{array}$} \\
\hline
\end{tabular}

Furthermore, the proportion of ${ }^{15} \mathrm{~N}$ in the leaves and stems in the apical part was also determined by the plant $\mathrm{N}$ concentration (PNC) of the apical part, but the proportion of ${ }^{15} \mathrm{~N}$ in the roots of the apical part was not (Fig. 4a-C). The proportion of ${ }^{15} \mathrm{~N}$ in the stems of the apical part gradually declined with increased PNC, and the proportion of ${ }^{15} \mathrm{~N}$ in leaves of the apical part was markedly elevated (Fig. $4 \mathrm{a}$ and b). In contrast, the partitioning proportion of ${ }^{15} \mathrm{~N}$ among organs of the basal part did not appear to depend on the PNC of the basal part (Fig. 4d-e).

Transport rate of ${ }^{15} \mathrm{~N}$ between ramets

Irrespective of the direction of ${ }^{15} \mathrm{~N}$ transport between connected ramets, the rate of ${ }^{15} \mathrm{~N}$ transport toward the recipient part was negatively related to $\triangle P N C\left(y=-15.10 x+19.10, R^{2}=0.26, P=0.021\right.$; Fig. 5). However, the rate of ${ }^{15} \mathrm{~N}$ transport toward the apical part was higher and reached up to averagely $20.9 \%$, while the rate of ${ }^{15} \mathrm{~N}$ transport toward the basal part only ranged between $0.2 \%$ and $6.3 \%$ (Fig. 5).

\section{Discussion}


This $\mathrm{N}$ isotope analysis clearly showed that $A$. philoxeroides allowed bi-directional movement of $\mathrm{N}$ between younger and older ramets within the same clone. Compared to the acropetal transport of $\mathrm{N}$ toward younger ramets, the basipetal transport of $\mathrm{N}$ toward older ramets was severely restricted, i.e., $20.9 \%$ of the ${ }^{15} \mathrm{~N}$ assimilated by the basal part was exported into the apical part via stolon connections, but only $1.7 \%$ of ${ }^{15} \mathrm{~N}$ assimilated by the apical part was exported. Such tremendous variation in the rate of $\mathrm{N}$ transportation in two opposite directions (i.e., acropetal versus basipetal $\mathrm{N}$ transportation) generally matches the acropetal nature of $\mathrm{N}$ sharing in $A$. philoxeroides and in other clonal species such as $A$. stolonifera and F. chiloensis (Marshall and Anderson-Taylor 1992; Alpert 1996, 2002). This is possibly because differences in resource uptake between young and old ramets could create a gradient in internal resource concentrations. Such a concentration gradient would drive the $\mathrm{N}$ transportation between connected ramets with a tendency for resources to move into relatively younger ramets (Dong et al. 2015). Furthermore, the hormones produced by the stolon apex may partly regulate the strong acropetal transport of internal resources within clonal fragments, as previously reported in non-clonal plants (Morris and Arthur 1987). Using the severance approach, previous work on clonal growth performance has also found that such clonal integration would significantly benefit the early growth of younger ramets in clonal fragments, at either zero or limited costs to the fitness of older ramets (Xiao et al. 2011; Roiloa et al. 2013; Dong et al. 2015; Xi et al. 2019; Wang et al. 2021).

The acropetal transport of $\mathrm{N}$ was also influenced by external $\mathrm{N}$ levels. When the external $\mathrm{N}$ level increased, the $\mathrm{N}$ concentration of plants at the ramet and whole-fragment levels also became higher (Appendix Table 2). And then, the apical part appeared to import less ${ }^{15} \mathrm{~N}$ that was assimilated by the basal part. The phenomenon was especially obvious in the accumulation of ${ }^{15} \mathrm{~N}$ in leaves and stems of apical parts, implying that an increase in external $\mathrm{N}$ level might, to some degree, weaken the source-sink relationship between younger and older ramets; thus, higher external $\mathrm{N}$ levels may alleviate the demand for $\mathrm{N}$ supply via stolon connections by young A. philoxeroides ramets (Dong et al. 2015; Xi et al. 2019). Furthermore, because there was a significant negative correlation between the rate of transport of ${ }^{15} \mathrm{~N}$ toward recipient ramets and $\triangle \mathrm{PNC}$, these results again suggest that the strength (rate) of acropetal transport of $\mathrm{N}$ (versus the amount of $\mathrm{N}$ transport) was negatively dependent on external $\mathrm{N}$ levels. Notably, compared to the acropetal transport of ${ }^{15} \mathrm{~N}$, the rate of basipetal transport of ${ }^{15} \mathrm{~N}$ was extremely lower; thus, this work also suggests that, even within the same clone, individual ramets of $A$. philoxeroides that are at different developmental ages might contribute $\mathrm{N}$ differently to other ramets. Here, compared to the stable $\mathrm{N}$ supply by older ramets, the younger ramets are more likely to be "selfish" and gradually decrease their low-efficient export of $\mathrm{N}$ as individual ramets matured (Wang et al. 2021).

Irrespective of acropetal or basipetal transport of $\mathrm{N}$ within clonal fragments, the partitioning proportion of ${ }^{15} \mathrm{~N}$ among organs in recipient ramets was organ-specific. As a typical stoloniferous clonal species, $A$. philoxeroides preferentially utilized a large proportion (approx. $90 \%$ ) of ${ }^{15} \mathrm{~N}$ imported from donor ramets to produce leaves and stems in recipient ramets, which often function as foraging organs of plants (e.g., performing the photosynthetic activity and ramet expansion). In contrast, the roots of $A$. philoxeroides often function as the belowground storage organ, and here required a low investment of N. Such a large 
investment of $\mathrm{N}$ in aboveground organs might, to some degree, accelerate the recruitment of vegetative offspring of $A$. philoxeroides and enhance the tolerance to aboveground disturbance (e.g., foliar herbivory and clipping)(Wilson et al. 2007; Rodríguez et al. 2018). This may allow this invasive species to colonize a wide range of habitats (Pan et al. 2006; Wu et al. 2016). By contrast, some other herbaceous perennial species (e.g., A. vinealis, $C$. canescens, and $P$. cuspidatum) tend to maintain a relatively higher proportion of $\mathrm{N}$ in nutrient uptake organs such leaves (rather than stems); this implies that the variation in life forms may partly determine the partitioning pattern of $\mathrm{N}$ among organs in different plant species (Hirose 1986, 1987; Boot et al. 1992).

The acropetal transport of ${ }^{15} \mathrm{~N}$ resulted in a higher proportion of ${ }^{15} \mathrm{~N}$ allocated to the aboveground organs of younger ramets and, simultaneously, to the roots of older ramets. In contrast, the basipetal transport of ${ }^{15} \mathrm{~N}$ did not modify the partitioning pattern of ${ }^{15} \mathrm{~N}$ among organs between connected ramets. Clonal integration may thus allow these connected ramets at different developmental stages to perform different tasks to optimize the efficiency of resource utilization within the same clone. Indeed, older ramets appear to specialize in $\mathrm{N}$ absorption and resource storage whereas younger ramets specialize in carbon assimilation and aboveground expansion (Stuefer 1998; D'Hertefeldt and Jonsdottir 1999). Such a response pattern is also attributed to the ontogenetic development of individual ramets, which is displayed as a "developmental division of labor" in clonal plants (Stuefer 1998; Roiloa et al. 2013). Previous work has reported that the similar ramet specialization is common in stoloniferous and rhizomatous species, as this response pattern has the potential to enhance resource uptake ability of clonal plants in homogeneous habitats (D'Hertefeldt and Jonsdottir 1999; Roiloa et al. 2013; Dong et al. 2015; Xi et al. 2019).

Finally, our work also tested whether the partitioning pattern of ${ }^{15} \mathrm{~N}$ among organs in recipient ramets was related to the $N$ concentration of recipient ramets. The results showed that for the majority $(4 / 6)$ of plant organs in recipient ramets (including the apical and basal parts), the distribution proportion of ${ }^{15} \mathrm{~N}$ was relatively fixed, with respect to the whole-part $\mathrm{N}$ concentration of the corresponding ramets. However, when younger ramets were the recipient, the distribution proportion of ${ }^{15} \mathrm{~N}$ of leaves and stems in younger ramets both strongly depended on the whole-part $\mathrm{N}$ concentration of younger ramets, although the relationship was sometimes positive for leaves but negative for stems. The results indicate that as the $\mathrm{N}$ concentration of plants increases at the higher external $\mathrm{N}$ level, younger ramets of $A$. philoxeroides can preferentially increase their investment of $\mathrm{N}$, which was imported via connections, into the constitution of leaf tissues. However, investment in leaves comes at the cost of stem development (as indicated by the decrease to the proportion of stem ${ }^{15} \mathrm{~N}$ in Fig. $4 \mathrm{~b}$ ). For other clonal plants such as P. cuspidatum, the developmental cost also possibly occurred in the root growth (Hirose 1987).

\section{Conclusions}

Although bi-directional $\mathrm{N}$ sharing did exist between the connected ramets, the $\mathrm{N}$ sharing via stolon connections tended to be acropetal in A. philoxeroides. The amount of acropetal transport of $\mathrm{N}$ was 
driven by the source-sink relationship between ramets, and it was weakened in the higher external $\mathrm{N}$ level. In contrast, the amount of basipetal transport of $\mathrm{N}$ was not affected by either the internal or external $\mathrm{N}$ levels. While the rate of acropetal transport may be independent, the rate of basipetal transport was negatively related to the internal gradient in $\mathrm{N}$ concentration. With respect to the partitioning of $\mathrm{N}$ among organs in A. philoxeroides, stems have the highest priority for $\mathrm{N}$ utilization, which may possibly facilitate offspring recruitment and the aboveground expansion of young ramets. A. philoxeroides also exhibited a developmental division of labor between ramets in homogeneous habitats, by preferentially allocating higher proportions of $\mathrm{N}$ to leaves in younger ramets and to roots in older ramets. Overall, clonal integration is of great importance for the early growth of young ramets in homogeneous habitats, and integration potentially contributes to the spread and abundance of stoloniferous clonal species in limited $\mathrm{N}$ environments.

\section{Declarations}

\section{Acknowledgements}

We thank Ting Fu for her assistance with the experiment. This work was supported by the Fundamental Research Funds for the National Natural Science Foundation of China $(31500331,32071525)$.

\section{Author's contributions}

BCD: designed, established and maintained the experiment; $B C D$ analysed the data; $B C D, P W$ and FLL drafted the manuscript and contributed to the fnal draft.

\section{Funding}

This work was supported by the Fundamental Research Funds for the National Natural Science Foundation of China (31500331, 32071525).

\section{Data availability}

The raw data are available on request to the corresponding author.

\section{Declarations Conficts of interest/competing interests}

The authors have no conficts of interest or competing interests to declare.

\section{References}

1. Alpert P (1996) Nutrient sharing in natural clonal fragments of Fragaria chiloensis. J Ecol 84:395406

2. Alpert $P$ (1999) Clonal integration in Fragaria chiloensis differs between populations: ramets from grassland are selfish. Oecologia 120:69-76 
3. Alpert P, Holzapfel C, Benson JM (2002) Hormonal modification of resource sharing in the clonal plant Fragaria chiloensis. Funct Ecol 16:191-197

4. Alpert P, Mooney HA (1986) Resource sharing among ramets in the clonal herb Fragaria chiloensis. Oecologia 70:227-233

5. Boot RGA, Schildwacht PM, Lambers H (1992) Partitioning of nitrogen and biomass at a range of $N$ addition rates and their consequences for growth and gas exchange in two perennial grasses from inland dunes. Physiol Plant 86:152-160

6. D'Hertefeldt T, Jonsdottir IS (1999) Extensive physiological integration in intact clonal systems of Carex arenaria. J Ecol 87:258-264

7. de Kroon H, Fransen B (1996) High levels of inter-ramet water translocation in two rhizomatous Carex species, as quantified by deuterium labelling. Oecologia 106:73-84

8. de Kroon H, van Groenendael J (1997) The ecology and evolution of clonal plants. Backhuys Publishers, Leiden

9. Dong B-C, Alpert P, Guo W, Yu F-H (2012) Effects of fragmentation on the survival and growth of the invasive, clonal plant Alternanthera philoxeroides. Biol Invasions 14:1101-1110

10. Dong B-C, Yu G-L, Guo W, Zhang M-X, Dong M, Yu F-H (2010) How internode length position and presence of leaves affect survival and growth of Alternanthera philoxeroides after fragmentation? Evol Ecol 24:1447-1461

11. Dong B-C, Alpert P, Zhang Q, Yu F-H (2015) Clonal integration in homogeneous environments increases performance of Alternanthera philoxeroides. Oecologia 179:393-403

12. Gao J-Q, Mo Y, Xu X-L, Zhang X-W, Yu F-H (2014) Spatiotemporal variations affect uptake of inorganic and organic nitrogen by dominant plant species in an alpine wetland. Plant Soil 381:271278

13. He X-H, Xu M-G, Qiu G-Y, Zhou J-B (2009) Use of ${ }^{15} \mathrm{~N}$ stable isotope to quantify nitrogen transfer between mycorrhizal plants. J Plant Ecol 2:107-118

14. Hikosaka K, Takashima T, Kabeya D, Hirose T, Kamata N (2005) Biomass allocation and leaf chemical defence in defoliated seedlings of Quercus serrata with respect to carbon-nitrogen balance. Ann Bot 95:1025-1032

15. Hirose T (1986) Nitrogen uptake and plant growth II: an empirical model of vegetative growth and partitioning. Ann Bot 58:487-496

16. Hirose T (1987) A vegetative plant growth model: adaptive significance of phenotypic plasticity in matter partitioning. Funct Ecol 1:195-202

17. Holm LG, Doll J, Holm E, Pancho J, Herberger J (1997) World weeds: natural histories and distribution. John Wiley and Sons, New York, pp 27-44

18. Huang Q-Q, Li X-X, Huang F-F, Wang R-L, Lu B, Shen Y-D, Fan Z-W, Lin P-Q (2018) Nutrient addition increases the capacity for division of labor and the benefits of clonal integration in an invasive plant. Sci Total Environ 643:1232-1238 
19. Hutchings MJ, Wijesinghe DK (1997) Patchy habitats division of labour and growth dividends in clonal plants. Trends Ecol Evol 12:390-394

20. Jia X, Pan X-Y, Li B, Chen J-K, Yang X-Z (2009) Allometric growth disturbance regime and dilemmas of controlling invasive plants: a model analysis. Biol Invasions 11:743-752

21. Julien M, Sosa A, Chan R, Schooler S, Traversa G (2012) Alternanthera philoxeroides (Martius) Grisebach-alligator weed. In: Julien M, McFadyen R, Cullen J (eds) Biological control of weeds in Australia. Csiro Publishing, Collingwood, pp 43-51

22. Marshall C, Anderson-Taylor G (1992) Mineral nutritional inter-relations amongst stolons and tiller ramets in Agrostis stolonifera L.. New Phytol:122, 339-347

23. Marshall C, Price E (1997) Sectoriality and its implications for physiological integration. In: de Kroon $\mathrm{H}$, van Groenendael J (eds) The ecology and evolution of clonal plants. Backbuys Pubishers, Leiden, pp 77-107

24. Morris DA, Arthur ED (1987) Auxin-induced assimilate translocation in the bean stem (Phaseolus vulgaris $\mathrm{L})$. Plant Growth Regul 5:169-181

25. Pan X-Y, Geng Y-P, Zhang W-J, Li B, Chen J-K (2006) The influence of abiotic stress and phenotypic plasticity on the distribution of invasive Alternanthera philoxeroides along a riparian zone. Acta Oecol 30:333-341

26. Rodríguez J, Calbi M, Roiloa SR, González L (2018) Herbivory induced non-local responses of the clonal invader Carpobrotus edulis are not mediated by clonal integration. Sci Total Environ 633:1041-1050

27. R Core Team (2021) R: a language and environment for statistical computing. R Foundation for Statistical Computing, Vienna, Austria

28. Roiloa SR, Antelo B, Retuerto R (2014) Physiological integration modifies $\delta 15 \mathrm{~N}$ in the clonal plant Fragaria vesca suggesting preferential transport of nitrogen to water-stressed offspring. Ann Bot 114:399-411

29. Roiloa SR, Rodríguez-Echeverría S, Freitas H, Retuerto R (2013) Developmentally-programmed division of labour in the clonal invader Carpobrotus edulis. Biol Invasions 15:1895-1905

30. Song Y-B, Yu F-H, Keser LH, Dawson W, Fischer M, Dong M, van Kleunen M (2013) United we stand divided we fall: a meta-analysis of experiments on clonal integration and its relationship to invasiveness. Oecologia 171:317-327

31. Stuefer JF (1998) Two types of division of labour in clonal plants: benefits costs and constraints. Perspect Plant Ecol 1:47-60

32. Wang J-Y, Xu T-T, Wang Y, Li G-Y, Abdullah I, Zhong Z-W, Liu J-S, Zhu W-Y, Wang L, Wang D-L, Yu F-H (2021) A meta-analysis of effects of physiological integration in clonal plants under homogeneous vs heterogeneous environments. Funct Ecol 35:578-589

33. Wang N, Yu F-H, Li P-X, He W-M, Liu F-H, Liu J-M, Dong M (2008) Clonal Integration affects growth photosynthetic efficiency and biomass allocation but not the competitive ability of the alien invasive Alternanthera philoxeroides under severe stress. Ann Bot 101:671-678 
34. Wang P, Alpert P, Yu F-H (2017) Clonal integration affects allocation in the perennial herb Alternanthera philoxeroides in N-limited homogeneous environments. Folia Geobot 52:303-315

35. Wilson JRU, Yeates A, Schooler S, Julien MH (2007) Rapid response to shoot removal by the invasive wetland plant alligator weed (Alternanthera philoxeroides). Environ Exp Bot 60:20-25

36. Wu H, Carrillo J, Ding J (2016) Invasion by alligator weed Alternanthera philoxeroides is associated with decreased species diversity across the latitudinal gradient in China. J Plant Ecol 9:311-319

37. Xi D-G, You W-H, Hu A-A, Huang P, Du D-L (2019) Developmentally programmed division of labor in the aquatic invader Alternanthera philoxeroides under homogeneous soil nutrients. Front Plant Sci $10: 485$

38. Xiao Y, Tang J-B, Qing H, Zhou C-F, Kong W-J, An S-Q (2011) Trade-offs among growth clonal and sexual reproduction in an invasive plant Spartina alterniflora responding to inundation and clonal integration. Hydrobiologia 658:353-363

39. Xu C-Y, Schooler SS, van Klinken RD (2010) Effects of clonal integration and light availability on the growth and physiology of two invasive herbs. J Ecol 98:833-844

40. Xu C-Y, Zhang W-J, Fu C-Z, Lu B-R (2003) Genetic diversity of alligator weed in China by RAPD analysis. Biodivers Conserv 12:637-645

41. Ye W-H, Li J, Cao H-L, Ge X-J (2003) Genetic uniformity of Alternanthera philoxeroides in South China. Weed Res 43:297-302

42. Yu F-H, Wang N, Alpert P, He W-M, Dong M (2009) Physiological integration in an introduced invasive plant increases its spread into experimental communities and modifies their structure. Am J Bot 96:1983-1989

43. Zhang H-J, Liu F-H, Wang R-Q, Jian L (2016) Roles of clonal integration in both heterogeneous and homogeneous habitats. Front Plant Sci 7:551

\section{Figures}

\section{Figure 1}

Experimental design. This experiment employed a two-way factorial design, with $\mathrm{N}$ level treatments (either 40 or $\left.120 \mathrm{mg} \mathrm{N} \mathrm{L}^{-1}\right)$ crossed with the position of ${ }^{15} \mathrm{~N}$ supply treatment $\left({ }^{15} \mathrm{NO}_{3}{ }^{+}\right.$supplied in either the apical part or the basal part; a, b, d, and e). We also included an additional control treatment at each $\mathrm{N}$ level (with no external ${ }^{15} \mathrm{NO}_{3}{ }^{+}$supplied in either the apical or basal parts; $\mathrm{c}$ and $\mathrm{f}$ ), to calculate the transport rate and partitioning pattern of $\mathrm{N}$ between connected ramets.

\section{Figure 2}


Effects of position of ${ }^{15} \mathrm{~N}$ supply $\left({ }^{15} \mathrm{~N}\right.$ was supplied in the apical [blank bar] or basal part [grey bar]) and $\mathrm{N}$ levels ( 40 or $120 \mathrm{mg} \mathrm{L}^{-1}$ ) on the amount of ${ }^{15} \mathrm{~N}$ of each plant organ in the apical part and the basal part of clonal fragments of Alternanthera philoxeroides. Error bar represents mean $\pm \mathrm{SE}$.

\section{Figure 3}

Effects of position of ${ }^{15} \mathrm{~N}$ supply $\left({ }^{15} \mathrm{~N}\right.$ was supplied in the apical [blank bar] or basal part [grey bar]) and $\mathrm{N}$ levels (40 and $120 \mathrm{mg} \mathrm{N} \mathrm{L}^{-1}$ ) on the partitioning proportion of ${ }^{15} \mathrm{~N}$ in each plant organ (plant-organ ${ }^{15} \mathrm{~N}$ amount/total ${ }^{15} \mathrm{~N}$ amount) in the apical part and the basal part of clonal fragments of Alternanthera philoxeroides. Error bar represents mean $\pm \mathrm{SE}$.

\section{Figure 4}

Linear regressions between partitioning proportion of ${ }^{15} \mathrm{~N}$ of each plant organ (the amount of ${ }^{15} \mathrm{~N}$ in plant organs/the total amount of ${ }^{15} \mathrm{~N}$ ) and PNC (the whole-part $\mathrm{N}$ concentration) in the apical part and the basal part of clonal fragments of Alternanthera philoxeroides. Different symbol represents different treatment, i.e., ${ }^{15} \mathrm{~N}$ was supplied in 0 the apical or $\mathbf{m}$ the basal parts grown at the $\mathrm{N}$ level of $40 \mathrm{mg} \mathrm{L}^{-1}$, and 0 the apical or $\square$ the basal parts grown at the $\mathrm{N}$ level of $120 \mathrm{mg} \mathrm{L}^{-1}$. The fitted equations, R-squared and $P$-values are given. The regression lines are shown only when $P$ values are less than 0.05 . 


$$
\mathrm{y}=-15.10 \mathrm{x}+19.10
$$

$R^{2}=0.26, P=0.021$

40

(1)

음

ठ 30

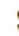

\section{Figure 5}

Linear regressions between the transport rate of ${ }^{15} \mathrm{~N}$ toward recipient ramets (calculated as the amount of ${ }^{15} \mathrm{~N}$ in recipient ramets/the amount of ${ }^{15} \mathrm{~N}$ in whole clonal fragment) and DPNC (calculated as the N concentration of the apical part - the $\mathrm{N}$ concentration of the basal part). Different symbol represents different treatment, i.e., ${ }^{15} \mathrm{~N}$ was supplied in 0 the apical or $\boldsymbol{\square}$ the basal parts grown at the $\mathrm{N}$ level of 40 $\mathrm{mg} \mathrm{L}^{-1}$, and $\bigcirc$ the apical or $\square$ the basal parts grown at the $\mathrm{N}$ level of $120 \mathrm{mg} \mathrm{L}^{-1}$. The fitted equation, the regression line, $\mathrm{R}$-squared and $P$-value are given. 


\section{Supplementary Files}

This is a list of supplementary files associated with this preprint. Click to download.

- Appendix.docx 